\title{
L'État, l'armée, la science. L'invention de la recherche publique en France (1763-1830)
}

Patrice Bret. Presses universitaires de Rennes, coll. « Carnot », 2002, 484 p.

\section{Olivier Martin}

\section{(2) OpenEdition}

Journals

Édition électronique

URL : https://journals.openedition.org/histoire-cnrs/424

DOI : $10.4000 /$ histoire-cnrs. 424

ISSN : 1955-2408

Éditeur

CNRS Éditions

Édition imprimée

Date de publication : 5 mai 2004

ISBN : 978-2-271-06145-4

ISSN : $1298-9800$

Référence électronique

Olivier Martin, «L'État, l'armée, la science. L'invention de la recherche publique en France

(1763-1830) », La revue pour l'histoire du CNRS [En ligne], 10 | 2004, mis en ligne le 07 mars 2006,

consulté le 20 mai 2021. URL : http://journals.openedition.org/histoire-cnrs/424 ; DOI : https://doi.org/

$10.4000 /$ histoire-cnrs.424

Ce document a été généré automatiquement le 20 mai 2021.

Comité pour l'histoire du CNRS 


\section{L'État, l'armée, la science. L'invention de la recherche publique en France (1763-1830)}

Patrice Bret. Presses universitaires de Rennes, coll. "Carnot », 2002, 484 p.

\section{Olivier Martin}

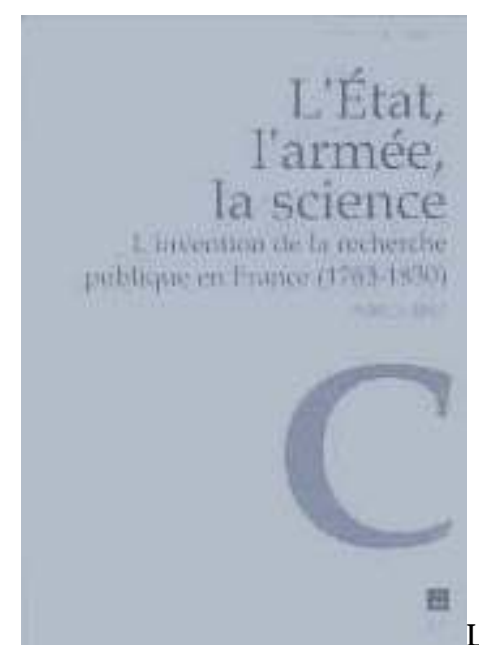

L'histoire longue du développement scientifique en France, et plus précisément l'histoire des institutions savantes, des politiques publiques qui les ont accompagnées, de leurs relations avec le secteur industriel et militaire, est encore assez largement inconnue. Les relations tissées entre l'État, les administrations, les organismes publics ou privés, les institutions savantes (académies) et les lieux de formation scientifiques (universités et grandes écoles), les entrepreneurs et industriels ont changé au fil des décennies; tout comme ont évolués les attentes, les modes d'action et les aspirations de ces différents acteurs : pour l'historien c'est à la fois un constat banal et une difficulté qu'il doit affronter pour arriver à penser, donc proposer un modèle de lecture du rôle des acteurs de cette histoire, de leurs interdépendances et des transformations des liens qu'ils tissent. 
1 Dans cet ouvrage très documenté, regorgeant d'études de cas détaillées, méticuleux dans sa démonstration, Patrice Bret offre un éclairage sur une période particulière de l'histoire de la recherche française: la période pré et post-révolutionnaire, durant laquelle les divers pouvoirs en place inventent les instruments lui permettant d'inciter l'application des sciences à la guerre. Mise en place durant les périodes républicaines, renforcée par l'Empire, l'État français s'est doté d'une recherche publique orientée vers les applications militaires. L'auteur montre comment la Révolution a institué, au sein de l'administration publique, des corps d'ingénieurs et de chercheurs; comment elle a fondé plusieurs grandes institutions scientifiques et techniques et notamment les grandes écoles. La mobilisation des savants rejoint ici celle de toute une nation contre la menace extérieure. Fervent promoteur de la science, Napoléon a à son tour favorisé le mariage des compétences scientifiques et les questions d'armement militaire. Ces évolutions mettent à mal le rôle central et incontournable de l'Académie des sciences qui prévalait sous la royauté, dans la tradition colbertiste: son monopole dans l'expertise des sciences et des techniques est mise à mal par les nouveaux corps techniques de l'État, par les académies de province, par des administrations de plus en plus investies par des savants. Ces derniers deviennent des rouages essentiels des processus décisionnels administratifs et politiques. Ajoutons également industriels. Un des principaux apports de l'ouvrage se situe dans ce dernier point: l'analyse des transformations de la production industrielle, elle aussi traversée par le souffle de l'esprit scientifique et de la rationalisation. Les corps techniques de l'État, avec leurs personnels savants, concourent au développement de la mécanisation, à l'avènement de la précision, à l'organisation scientifique du travail, à la formation des cadres et à l'uniformisation de cette formation, à la standardisation de la production. Cette normalisation de la production, des matériels, des procédés ainsi que «des personnels » transforme en profondeur l'industrie nationale (et spécifiquement l'industrie des armes).

2 Cette période est d'autant plus riche en enseignements que divers modèles d'organisation de la science se succèdent assez rapidement et que, si nous suivons le travail désormais classique de Charles Gillispie ${ }^{1}$, cette période est celle de l'apogée de la science française : elle est prépondérante dans le monde et le rayonnement scientifique français en Europe atteint un sommet. Elle l'est également car, si nous suivons l'auteur, le paysage qui se met alors en place est celui qui prévaudra pendant plus d'un siècle : la France venait d'inventer la « recherche publique ». On connaît le succès qu'auront ce modèle et ses dérivés, durant les XIX ${ }^{\mathrm{e}}$ puis $\mathrm{XX}^{\mathrm{e}}$ siècle dans le monde occidental.

3 Méticuleux, nuancé et prudent, l'ouvrage l'est incontestablement. Peut-être au détriment d'efforts de synthèse et de tentatives de modélisations plus fortes et plus simples des faits étudiés. Espérons néanmoins que l'ouvrage trouvera un public dépassant le cercle des spécialistes de cette époque ou de ces questions. 


\section{NOTES}

1. C. Gillispie, Science and Policy in France at the End of the Old Regime, Princeton, Princeton University Press, 1980.

INDEX

Mots-clés : science, savant, recherche, état, armée, publique, institutions, administration, corps, ingénieur, personnel

\section{AUTEUR}

\section{OLIVIER MARTIN}

Maître de conférences à l'université de Paris V 